\title{
Tezosentan Decreases Pulmonary Artery Pressure and Improves Survival Rate in an Animal Model of Meconium Aspiration
}

\author{
RALF GEIGER, WERNER PAJK, NIKOLAUS NEU, STEPHAN MAIER, AXEL KLEINSASSER, SOHRAB FRATZ, \\ SALVADOR NAVARRO-PSIHA, VIKTORIA FISCHER, BENEDIKT TREML, AND ALEXANDER LOECKINGER
}

\begin{abstract}
Clinical Divisions of Pediatric Cardiology [R.G., V.F.], Pediatric Intensive Care [N.N.], Neonatology [S.N.], Anesthesiology and Critical Care Medicine [W.P., S.M., A.K., B.T., A.L.], Innsbruck Medical University, 6020 Innsbruck, Austria; Department of Pediatric Cardiology and Congenital Heart Disease [S.F.], German Heart Center Munich, 80636 Munich, Germany
\end{abstract}

\begin{abstract}
Acute pulmonary arterial hypertension in acute lung injury aggravates the clinical course and complicates treatment. Increased release and turnover of endogenous endothelin- 1 is known to be a major determinant in the pathophysiology of pulmonary arterial hypertension of various etiologies. We tested whether intravenous tezosentan, a dual endothelin receptor antagonist, reduced pulmonary artery pressure in a pig model of acute lung injury induced by meconium aspiration. Acute pulmonary arterial hypertension was induced in 12 anesthetized and instrumented pigs by instillation of human pooled meconium in a $20 \%$ solution. Hemodynamic and gas exchange parameters were recorded every $30 \mathrm{~min}$. Six animals received tezosentan $5 \mathrm{mg} / \mathrm{kg}$ after 0 and $90 \mathrm{~min}$; six animals served as controls. Tezosentan led to a decrease of mean pulmonary artery pressure (PAP) from $33.4 \pm 4.0 \mathrm{~mm} \mathrm{Hg}$ to $24.7 \pm 2.1 \mathrm{~mm} \mathrm{Hg}$ and pulmonary vascular resistance (PVR) from $7.8 \pm 1.4 \mathrm{~mm} \mathrm{Hg}$. $\mathrm{L}^{-1} \cdot \min \cdot \mathrm{m}^{2}$ to $5.2 \pm 0.7 \mathrm{~mm} \mathrm{Hg} \cdot \mathrm{L}^{-1} \cdot \mathrm{min} \cdot \mathrm{m}^{2}$. All animals treated with tezosentan survived, whereas in the control group four out of six animals died. Tezosentan improved survival and decreased pulmonary artery pressure in a porcine model of acute pulmonary arterial hypertension after meconium aspiration. Tezosentan has the potential for effective pharmacological treatment of pulmonary arterial hypertension following acute lung injury. (Pediatr Res 59: 147-150, 2006)
\end{abstract}

A cute pulmonary arterial hypertension accompanies acute lung injury (ALI) and acute respiratory distress syndrome. Aspiration of meconium induces acute parenchymal lung disease with diffuse inflammation of the alveolarcapillary membrane. Obliteration of the pulmonary capillary bed and subsequent pulmonary vasoconstriction induces pulmonary arterial hypertension, which may be severe and may lead to right ventricular failure and subsequent multiorgan failure (1-4). Effective pharmacological therapy is limited. Endothelial dysfunction of the small pulmonary arteries is known to play a key role in the pathophysiology of pulmonary arterial hypertension of various etiologies (5-8). Impaired production of vasodilative mediators, such as nitric oxide and

Received March 17, 2005; accepted July 14, 2005.

Correspondence: Ralf Geiger, M.D., Clinical Division of Pediatric Cardiology, Innsbruck Medical University, Anichstrasse 35, 6020 Innsbruck, Austria; e-mail: ralf.geiger@ uibk.ac.at

This research was supported by Grant 110 from MFF/TILAK, General Hospital, Innsbruck, Austria. Tezosentan was provided by Actelion Pharmaceuticals, Allschwil, Switzerland.

DOI: 10.1203/01.pdr.0000191813.60977.bf prostacyclin, along with increased production of vasoconstrictive endothelin-1 (ET-1) are regarded as key factors in the pathophysiology of pulmonary hypertensive disorders (9). ET-1 is a polypeptide, which is released by vascular endothelial cells in response to hypoxic and acute or chronic toxic lung injury $(10,11)$. Induction of transcription of ET-1 mRNA and synthesis and secretion of ET-1 takes place within minutes after promoting stimuli by, for example, hypoxia, cytokines, adhesion molecules, and catecholamines (12). ET-1 exerts a direct and sustained vasoconstrictive effect via $\mathrm{ET}_{\mathrm{A}}$ receptors, expressed on vascular smooth muscle cells. Activation of $\mathrm{ET}_{\mathrm{B}}$ receptors, expressed on vascular endothelial cells, mediates pulmonary endothelin clearance and induces production of nitric oxide and prostacyclin, which both exert vasodilative effects. In addition, ET-1 stimulates proliferation of vascular smooth muscle cells and acts as a proinflammatory mediator (13). Indeed, up-regulation of ET-1 gene expression and increased levels of circulating ET-1 have been demonstrated in animal models of meconium aspiration $(14,15)$ and in hypoxia-induced pulmonary arterial hypertension (16). Therefore, blocking the effects of ET-1 should attenuate the concomitant rise of pulmonary artery pressure in acute lung injury and thus diminish stress imposed on the right heart. The orally active combined $\mathrm{ET}_{\mathrm{A}}$ and $\mathrm{ET}_{\mathrm{B}}$ receptor antagonist bosentan has been shown to be of benefit in the treatment of pulmonary arterial hypertension in humans $(17,18)$. In the clinical situation of profound hemodynamic impairment after ALI, where pharmacodynamics might be influenced by variable enteral drug uptake, an injectable agent would be of advantage.

Recently, a water-soluble combined $\mathrm{ET}_{\mathrm{A}}$ and $\mathrm{ET}_{\mathrm{B}}$ receptor antagonist for parenteral use, tezosentan (Actelion Pharmaceuticals, Allschwil, Switzerland), has been shown to exert pulmonary vasodilative effects in oleic acid-induced pulmonary arterial hypertension in dogs and in lambs with acute and chronic pulmonary arterial hypertension $(19,20)$. The aim of

Abbreviations: CVP, central venous pressure; $\mathbf{F i o}_{2}$, inspired oxygen fraction; PAP, mean pulmonary artery pressure; PCWP, mean pulmonary capillary wedge pressure; PVR, pulmonary vascular resistance; PVR/SVR, pulmonary to systemic vascular resistance ratio 
this study was to test the hypothesis whether tezosentan reduces mean PAP in a pig model of acute pulmonary arterial hypertension secondary to meconium aspiration.

\section{METHODS}

Experimental preparation. The Austrian Federal Animal Investigational Committee approved all experiments, and animals were managed in accordance with the National Institutes of Health guidelines. First-pass human meconium was obtained, suspended in physiologic sodium chloride at a concentration of $20 \%$, filtered, and stored in $20 \mathrm{~mL}$ syringes at $-20^{\circ} \mathrm{C}$. The meconium was thawed in hot water immediately before use. The study was performed on healthy, 4-wk-old white farm pigs weighing $17-23 \mathrm{~kg}$. Anesthesia was induced with ketamine $(50 \mathrm{mg} / \mathrm{kg}$ i.m. $)$ and atropine $(0.01 \mathrm{mg} / \mathrm{kg}$ i.m.), followed by i.v. propofol $(2-4 \mathrm{mg} / \mathrm{kg})$. After the trachea had been intubated, lungs were ventilated in volume-controlled mode (Evita 4, Dräger, Telford, PA) at an $\mathrm{Fio}_{2}$ of 0.4 and a tidal volume (VT) of $10 \mathrm{~mL} / \mathrm{kg}$ at 20 breaths/min, positive end-expiratory pressure set at $5 \mathrm{~mm} \mathrm{Hg}$. VT was then adjusted to achieve a $\mathrm{PaCO}_{2}$ between 35 and $40 \mathrm{~mm} \mathrm{Hg}$, resulting in a minute ventilation of $150-170 \mathrm{~mL} / \mathrm{kg} / \mathrm{min}$. Anesthesia was maintained with propofol $(10-15 \mathrm{mg} / \mathrm{kg} / \mathrm{h})$ and piritramide boluses (15 mg each). Ringer's solution (6 $\mathrm{mL} / \mathrm{kg} / \mathrm{h})$ and a $3 \%$ gelatin solution $(4 \mathrm{~mL} / \mathrm{kg} / \mathrm{h})$ were administered throughout the procedure. A standard lead II ECG was used to monitor cardiac rhythm. Body temperature was maintained between $38^{\circ} \mathrm{C}$ and $39^{\circ} \mathrm{C}$ by using an electric heating blanket.

A $4 \mathrm{~F}$ catheter was advanced into a femoral artery for withdrawal of arterial blood and for measuring arterial blood pressure. A 7F pulmonary artery catheter was advanced from the internal jugular vein into the pulmonary artery to measure mean PAP, PCWP, CVP, and cardiac output by the thermodilution technique (10 mL saline in triplicate) and to withdraw mixed venous blood. All catheters were filled with saline and connected to pressure transducers zeroed to ambient pressure at the level of the right atrium.

Experimental protocol. Twelve animals where randomly assigned to receive either tezosentan or to serve as controls. After preparation of the animals a stabilization phase of $30 \mathrm{~min}$ was allowed, thereafter baseline measurements (hemodynamics, blood gases) were taken. Hemodynamics and blood gas samples were performed every $30 \mathrm{~min}$. Each pig received a first deep intratracheal instillation of a $20 \%$ solution of pooled human meconium of $0.5 \mathrm{~mL} / \mathrm{kg}$ and doses of $0.25 \mathrm{~mL} / \mathrm{kg}$ were titrated up to a maximum of 2.5 $\mathrm{mL} / \mathrm{kg}$. After instillation of meconium, peak inspiratory pressure was increased from mean $16.5 \pm 1.2$ mbar to $25.3 \pm 3.4$ mbar and a $\mathrm{Fio}_{2}$ of 1.0 was given over a 3-min period to counteract the effects of acute hypoxia, i.e. severe pulmonary hypertension and acute right heart failure. Thereafter, $\mathrm{FiO}_{2}$ was reset to 0.4 and no further respiratory adjustments were done for the remaining experimental observation. Meconium instillation was not further continued when PAP had increased to values two times above baseline. After 60 min of steady state pulmonary arterial hypertension $(\min 0)$ hemodynamics and blood gases were measured and animals assigned to the tezosentan group received $5 \mathrm{mg} / \mathrm{kg}$ tezosentan bolus injection and a second dose 90 min later. Animals assigned to the control group received no further intervention.
Respirator settings were not changed during the study period in none of the animals. At the end of the study, animals were killed using pentobarbital. Thereafter, the heart together with the proximal parts of the great arteries was removed and inspected to rule out any anatomical intra- or extracardial shunt connection. Pulmonary and vascular resistance was calculated using standard formulas. Values were related to body surface area by converting factor $0.0947 \cdot \mathrm{kg}^{2 / 3}(21)$.

Statistical analysis. A two-way ANOVA was used to determine inter- and intragroup differences. Significant results were analyzed post hoc with the Newman-Keuls and Fisher's exact tests. Data are presented as mean \pm SD, a value of $p<0.05$ was considered significant.

\section{RESULTS}

Changes from baseline to min 0. Meconium instillation led to an increase of PAP from mean $19.8 \pm 2.0 \mathrm{~mm} \mathrm{Hg}$ to 33.4 $\pm 3.4 \mathrm{~mm} \mathrm{Hg}(70 \%)$ and PVR from mean $3.8 \pm 1.0 \mathrm{~mm} \mathrm{Hg}$ $\cdot \mathrm{L}^{-1} \cdot \min \cdot \mathrm{m}^{2}$ to $8.1 \pm 1.6 \mathrm{~mm} \mathrm{Hg} \cdot \mathrm{L}^{-1} \cdot \min \cdot \mathrm{m}^{2}(113 \%)$, without any significant intergroup differences (Table 1).

Changes from min 0 to $\min 210$. None of the animals of the tezosentan group died during this observation period in contrast to the control group, where four out of six animals died $(p=0.03)$. Death had occurred before $60 \mathrm{~min}$ (two animals), $90 \mathrm{~min}$, and $180 \mathrm{~min}$ (one animal, respectively) (Fig. 1). Immediately after bolus injection of tezosentan, animals had a significant decrease of mean PAP (33.4 $\pm 4.0 \mathrm{~mm} \mathrm{Hg}$ to 24.7 $\pm 2.1 \mathrm{~mm} \mathrm{Hg}, p=0.001$ ) and PVR (from $7.8 \pm 1.4 \mathrm{~mm} \mathrm{Hg}$ $\cdot \mathrm{L}^{-1} \cdot \mathrm{min} \cdot \mathrm{m}^{2}$ to $5.2 \pm 0.7 \mathrm{~mm} \mathrm{Hg} \cdot \mathrm{L}^{-1} \cdot \mathrm{min} \cdot \mathrm{m}^{2}, p=$ 0.0003). These effects were continual throughout the study period. The second dose of tezosentan did not significantly alter the parameters measured. In striking contrast, PAP and PVR continued to increase within the first $30 \mathrm{~min}$ in the control animals: mean PAP from $34.6 \pm 3.2 \mathrm{~mm} \mathrm{Hg}$ to 38.0 $\pm 5.7 \mathrm{~mm} \mathrm{Hg}$ and mean PVR from $8.3 \pm 1.8 \mathrm{~mm} \mathrm{Hg} \cdot \mathrm{L}^{-1}$ $\cdot \min \cdot \mathrm{m}^{2}$ to $9.7 \pm 3.0 \mathrm{~mm} \mathrm{Hg} \cdot \mathrm{L}^{-1} \cdot \min \cdot \mathrm{m}^{2}$. $\mathrm{PaCO}_{2}$ and $\mathrm{pH}$ did not differ between the groups nor did they change substantially within each group, whereas $\mathrm{paO}_{2}$ decreased significantly in both groups alike (Table 1).

\section{DISCUSSION}

The results of the present study show that dual ET-1 receptor-blocker tezosentan decreased PAP in experimental

Table 1. Hemodynamic and ventilatory data at baseline, after instillation of meconium ( 0 min), after 30 min, and at the end of observation $(210 \mathrm{~min})$ in controls and in animals receiving tezosentan at 0 min and at $90 \mathrm{~min}$

\begin{tabular}{|c|c|c|c|c|c|c|c|c|}
\hline & \multicolumn{4}{|c|}{ Control } & \multicolumn{4}{|c|}{ Tezosentan at $0 \mathrm{~min}$ and at $90 \mathrm{~min}$} \\
\hline $\begin{array}{l}\operatorname{PVR}\left(\mathrm{mm} \mathrm{Hg} \cdot \mathrm{L}^{-1} .\right. \\
\left.\quad \min ^{-1} \cdot \mathrm{m}^{-2}\right)\end{array}$ & $3.8(1.4)$ & $8.3(1.8)$ & $9.7(3.0)$ & $10.2(0.3)$ & $3.8(0.6)$ & $7.8(1.4)$ & $5.2(0.7)^{* *}$ & $5.4(0.8)$ \\
\hline $\begin{array}{l}\mathrm{SVR}\left(\mathrm{mm} \mathrm{Hg} \cdot \mathrm{L}^{-1} \cdot\right. \\
\left.\min ^{-1} \cdot \mathrm{m}^{-2}\right)\end{array}$ & $29.1(6.0)$ & $27.6(2.2)$ & $29.4(1.6)$ & $24.5(9.3)$ & $28.6(5.9)$ & $23.8(6.8)$ & $20.7(5.5)^{*}$ & $17.6(3.6)$ \\
\hline PCWP (mm Hg) & $10.2(1.3)$ & $9.8(1.1)$ & $10.4(1.1)$ & $11.0(0.1)$ & $9.5(1.4)$ & $8.7(2.3)$ & $8.7(2.3)$ & $9.2(1.8)$ \\
\hline CVP (mm Hg) & $8.7(1.5)$ & $8.2(1.3)$ & $8.2(1.5)$ & $10.0(1.4)$ & $8.8(1.2)$ & $9.0(2.0)$ & $8.5(1.6)$ & $10.2(2.5)$ \\
\hline $\mathrm{CI}\left(\mathrm{L} \cdot \mathrm{min}^{-1} \cdot \mathrm{m}^{-2}\right)$ & $2.73(0.44)$ & $3.03(0.31)$ & $2.91(0.53)$ & $2.71(0.13)$ & $2.48(0.55)$ & $3.30(0.69)$ & $3.12(0.65)$ & $3.12(0.79)$ \\
\hline $\mathrm{PaO}_{2}(\mathrm{~mm} \mathrm{Hg})$ & $162.8(16.4)$ & $60.0(14.4)$ & $58.9(13.8)$ & $51.2(7.6)$ & $167.9(5.2)$ & $66.1(13.0)$ & $59.2(6.6)$ & $44.4(4.7)$ \\
\hline $\mathrm{PaCO}_{2}(\mathrm{~mm} \mathrm{Hg})$ & $37.6(3.9)$ & $50.5(6.0)$ & $50.4(7.1)$ & $50.3(0.5)$ & $36.7(2.6)$ & $45.7(8.2)$ & $43.1(11.1)$ & 44.7 (7.4) \\
\hline $\mathrm{pH}$ & $7.469(0.030)$ & $7.316(0.080)$ & $7.347(0.085)$ & $7.347(0.091)$ & $7.494(0.049)$ & $7.396(0.094)$ & $7.430(0.105)$ & $7.421(0.074)$ \\
\hline
\end{tabular}

Data are presented as mean (SD). BP, blood pressure; CI, cardiac index.

Intergroup significance of $* * p<0.01$ and $* p<0.05$. 


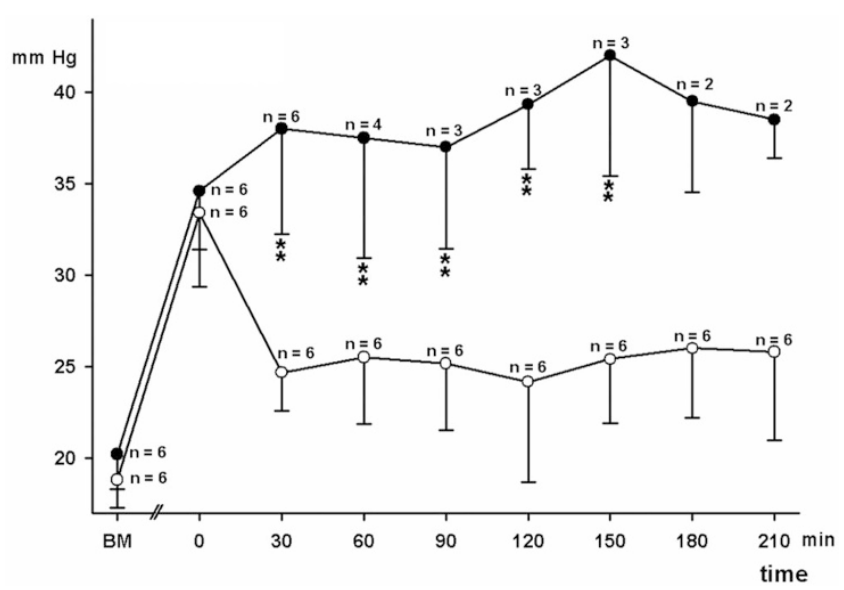

Figure 1. Mean pulmonary artery pressure in animals treated with tezosentan (open circles) and controls (solid circles). Bars represent SD. Four out of six animals in the control group died during the observation period, whereas all animals receiving tezosentan survived. $B M$, before meconium. Intergroup significance of $* * p<0.01$ and $* p<0.05$.

meconium-induced acute pulmonary arterial hypertension, albeit with noteworthy systemic effects. Tezosentan recently has been shown to exert pulmonary vasodilative effects in oleic acid-induced pulmonary arterial hypertension in dogs and in acute and chronic pulmonary arterial hypertension in lambs $(19,20)$. At a dose of $5 \mathrm{mg} / \mathrm{kg}$, tezosentan induced maximum decrease of mean PAP (16\%) and PVR (21\%) in U46619 (thromboxane)-induced pulmonary arterial hypertension without decrease of systemic blood pressure (20). Therefore we chose this dose in our study. Because of its short half-life of $<1 \mathrm{~h}$ in primates (22) and the reported short duration of action in experimental pulmonary hypertension (20), a second bolus injection of tezosentan was given in our study. However, this second bolus did not lead to further pulmonary vasodilation nor did we observe an increase of PAP or PVR before the second dose. Pulmonary vasodilation occurred within minutes after the first bolus injection of tezosentan and lasted throughout the study period. It could be argued that a selective $\mathrm{ET}_{\mathrm{A}}$ receptor antagonist would produce more pronounced vasodilation. A selective $\mathrm{ET}_{\mathrm{A}}$ agent would not antagonize $\mathrm{ET}_{\mathrm{B}}$ receptor stimulation-coupled nitric oxidemediated vasodilation and might be preferential by interfering less with endothelin clearance. Selective $\mathrm{ET}_{\mathrm{A}}$ receptor blockade by $\mathrm{BQ}-123$ before or after inhalation of nitric oxide recently has been shown to decrease PAP and PVR in a model of meconium-induced acute pulmonary arterial hypertension in neonatal pigs (15). Comparing the effects of selective and unselective endothelin receptor blockade in one experimental setting would be of interest. In our study, vasodilation was not solely for the pulmonary circulation, as systemic pressure and vascular resistance also decreased, although to a lesser extent. This is in accordance with other studies and might indicate a systemic role of endothelin in the regulation of the vascular tone $(20,23,24)$. PVR/SVR decreased after the first dose of tezosentan but increased to some extent after the second dose, mainly due to a decrease of SVR. In controls, PVR/SVR progressively increased due to rising PVR. These observed systemic effects of tezosentan did not negatively influence survival rate. Systemic hypotensive effects of tezosentan are known from a clinical trial in acute heart failure, where tezosentan led to higher incidence of hypotension-related symptoms and renal failure (24). In our study, $\mathrm{PaO}_{2}$ progressively decreased in both groups. This decrease was expected from the experimental setting, which did not allow for further correction of pulmonary gas exchange, except immediately after meconium aspiration. The decrease of $\mathrm{PaO}_{2}$ seems to be greater in the tezosentan-treated animals than in controls, but the small number of control animals alive at the end of the observation period makes meaningful interpretation difficult. Our experiment was designed to analyze the effects of tezosentan; we did not intend to treat ALI clinically. Possible tezosentan effects on $\mathrm{PaO}_{2}$ and systemic blood pressure clearly need to be taken into account. How these potentially harmful effects translate into clinics needs further investigations, especially when counteracted by ventilatory adjustments and vasoconstrictive agents, which are part of routine management in ALI. Selective inhaled vasodilators, like nitric oxide or aerosolized prostacyclins are comparable to each other in improving ventilation/perfusion matching and reducing PAP in patients with lung injury. Inhaled vasodilators would cause minimal systemic vasodilation, although adverse systemic effects of prostacyclins due to "spillover" into the systemic circulation have been reported (25). Delivery of aerosolized prostacyclins may be technically cumbersome with unpredictable dose variability. Intravenous tezosentan would not interfere with ventilator function and allow for titration of effective drug level. Studies comparing intravenous to inhaled treatment modalities in experimental ALI are needed. Two-thirds of our control animals died of acute right heart failure. Massive tricuspid regurgitation heralded the sudden decrease of PAP and subsequent low cardiac output. The pulmonary vasodilative effects of tezosentan alone prevented acute right heart decompensation. Conventional mechanical ventilation has been shown to perpetuate lung injury by imposing volutrauma and atelectrauma $(1,4)$. In light of currently proposed lung-protective ventilation strategies in the treatment of ALI, endothelin receptor blockade by tezosentan might be a powerful means to counteract the life-threatening effects of acute pulmonary hypertension and facilitate more protective ventilation strategies. Further studies should address the acute effects of dual endothelin receptor blockade in combination with potentially synergistic selective pulmonary vasodilative agents.

Study limitations. A limitation of our study is that the animal model investigated does not generally reflect the clinical situation, as there is no aspiration of meconium beyond the peripartal period in humans. In addition, pharmacological effects might differ in newborn pigs from those in 4-wk-old animals, where PAP and PVR have almost reached their nadir (26). Nevertheless, meconium aspiration uniformly induced profound and predictable changes of pulmonary gas exchange and hemodynamics. 


\section{CONCLUSION}

This study investigated the pulmonary hemodynamic effects of the intravenous dual receptor blocker tezosentan in a porcine model of acute pulmonary arterial hypertension secondary to meconium aspiration. Tezosentan decreased pulmonary artery pressure and resistance and improved survival rate. Tezosentan has the potential for effective pharmacological treatment of meconium-induced pulmonary arterial hypertension, which deserves further investigation.

\section{REFERENCES}

1. Ware LB, Matthay MA 2000 The acute respiratory distress syndrome. N Engl J Med 342:1334-1349

2. Kinsella JP, Abman SH 1995 Recent developments in the pathophysiology and treatment of persistent pulmonary hypertension of the newborn. J Pediatr 126:853864

3. Flori HR, Glidden DV, Rutherford GW, Matthay MA 2005 Pediatric acute lung injury: prospective evaluation of risk factor associated with mortality. Am J Respir Crit Care Med 171:995-1001

4. Adhikari N, Burns KE, Meade MO 2004 Pharmacologic treatments for acute respiratory distress syndrome and acute lung injury: systematic review and metaanalysis. Treat Respir Med 3:307-328

5. Yanagisawa M, Kurihara H, Kimura S, Tomobe Y, Kobayashi M, Mitsui Y, Yazaki Y, Goto K, Masaki T 1988 A novel potent vasoconstrictor peptide produced by vascular endothelial cells. Nature 332:411-415

6. Giaid A, Yanagisawa M, Langleben D, Michel RP, Levy R, Shennib H, Kimura S, Masaki T, Duguid WP, Stewart DJ 1993 Expression of endothelin-1 in the lungs of patients with pulmonary hypertension. N Engl J Med 328:1732-1739

7. Humbert M, Morrell NW, Archer SL, Stenmark KR, MacLean MR, Lang IM, Christman BW, Weir EK, Eickelberg O, Voelkel NF, Rabinovitch M 2004 Cellular and molecular pathobiology of pulmonary arterial hypertension. J Am Coll Cardiol 43:13S-24S

8. Higenbottam TW, Laude EA 1998 Endothelial dysfunction providing the basis for the treatment of pulmonary hypertension: Giles F. Filley lecture. Chest 114:72S-79S

9. Humbert M, Sitbon O, Simonneau G 2004 Treatment of pulmonary arterial hypertension. N Engl J Med 351:1425-1436

10. Kourembanas S, Marsden PA, McQuillan LP, Faller DV 1991 Hypoxia induces endothelin gene expression and secretion in cultured human endothelium. J Clin Invest 88:1054-1057
11. Fagan KA, McMurtry IF, Rodman DM 2001 Role of endothelin-1 in lung disease. Respir Res 2:90-101

12. Galie N, Manes A, Branzi A 2004 The endothelin system in pulmonary arterial hypertension. Cardiovasc Res 61:227-237

13. Rubanyi GM, Polokoff MA 1994 Endothelins: molecular biology, biochemistry, pharmacology, physiology, and pathophysiology. Pharmacol Rev 46:325-415

14. Kuo CY 2001 Endothelin-A receptor antagonist prevents neonatal pulmonary hypertension in meconium aspiration in piglets. J Formos Med Assoc 100:420-423

15. Shekerdemian LS, Penny DJ, Ryhammer PK, Reader JA, Ravn HB 2004 Endothelin-A receptor blockade and inhaled nitric oxide in a porcine model of meconium aspiration syndrome. Pediatr Res 56:353-358

16. Donahue DM, Lee ME, Suen HC, Quertermous T, Wain JC 1994 Pulmonary hypoxia increases endothelin-1gene expression in sheep. J Surg Res 57:280-283

17. Rubin LJ, Badesch DB, Barst RJ, Galie N, Black CM, Keogh A, Pulido T, Frost A Roux S, Leconte I, Landzberg M, Simonneau G 2002 Bosentan therapy for pulmonary arterial hypertension. N Engl J Med 346:896-903

18. Sitbon O, Badesch DB, Channick RN, Frost A, Robbins IM, Simonneau G, Tapson VF, Rubin LJ 2003 Effects of the dual endothelin receptor antagonist bosentan in patients with pulmonary arterial hypertension: a 1-year follow-up study. Chest $124: 247-254$

19. Wang L, Zhu du M, Su X, Bai CX, Ware LB, Matthay MA 2004 Acute cardiopulmonary effects of a dual-endothelin receptor antagonist on oleic acid-induced pulmonary arterial hypertension in dogs. Exp Lung Res 30:31-42

20. Fitzgerald RK, Oishi P, Ovadia B, Ross GA, Reinhartz O, Johengen MJ, Fineman JR 2004 Tezosentan, a combined parenteral endothelin receptor antagonist, produces pulmonary vasodilation in lambs with acute and chronic pulmonary hypertension. Pediatr Crit Care Med 5:571-577

21. Brody S, Kibler HH 1944 Resting energy metabolism and pulmonary ventilation in growing swine. Missouri Univ Agr Expt Sta Res Bull 380:2-20

22. Clozel M, Ramuz H, Clozel JP, Breu V, Hess P, Löffler BM, Coassolo P, Roux S 1999 Pharmacology of tezosentan, new endothelin receptor antagonist designed for parenteral use. J Pharmacol Exp Ther 290:840-846

23. Chin A, Radhakrishnan J, Fornell L, John E 2001 Effects of tezosentan, a dual endothelin receptor antagonist, on the cardiovascular and renal system of neonatal piglets. J Pediatr Surg 36:1824-1828

24. O'Connor CM, Gattis WA, Adams KF Jr, Hasselblad V, Chandler B, Frey A, Kobrin I, Rainisio M, Shah MR, Teerlink J, Gheorghiade M 2003 Tezosentan in patients with acute heart failure and acute coronary syndromes: results of the Randomized Intravenous TeZosentan Study (RITZ-4). J Am Coll Cardiol 41:1452-1457

25. Siobal M 2004 Aerosolized prostacylins. Respir Care 49:640-652

26. Haworth SG, Hislop AA 1981 Adaptation of the pulmonary circulation to extrauterine life in the pig and its relevance to the human infant. Cardiovasc Res $15: 108-119$ 